\title{
Case of Prominent Periorbital Vein after Lower Eyelid Blepharoplasty Treated with a Long-pulse 1,064-nm Neodymium: Yttrium-aluminum-garnet Laser
}

Wan Jin Kim

Han Kyoung Cho ${ }^{1}$

Sang Ju Lee ${ }^{2}$

${ }^{1}$ Department of Dermatology, Hanyang University Medical Center, Myongji Hospital, Goyang, Korea

${ }^{2}$ Yonsei Star Skin \& Laser Clinic, Seoul, Korea
Received October 18, 2020

Accepted November 22, 2020

\footnotetext{
Correspondence

Han Kyoung Cho

Department of Dermatology, Hanyang University Medical Center, Myongji Hospital, 55 Hwasu-ro 14 gil, Deogyang-gu, Goyang 10475, Korea

Tel.: +82-31-810-7050

Fax: +82-31-810-7057

E-mail: trpchk@hanmail.net

(c) Korean Society for Laser Medicine and Surgery

(@) This is an open access article distributed under the terms of the Creative Commons Attribution NonCommercial License (http://creativecommons.org/ licenses/by-nc/4.0) which permits unrestricted noncommercial use, distribution, and reproduction in any medium, provided the original work is properly cited.
}

Lower eyelid blepharoplasty is a popular facial rejuvenation surgery that restores the infraorbital region. The procedure is performed by removing excessive fatty tissues, muscles, and other unnecessary structures. The structure of the eyelid differs from person to person and is quite complex; therefore, numerous side effects are expected. Common lower eyelid blepharoplasty complications are asymmetrical faces, retrobulbar hemorrhage, blurred vision, and ectropion. This paper reports a case of a prominent periorbital vein after lower eyelid blepharoplasty. The prominent periorbital vein after surgery is a rare side effect that has not been reported to the best of the author's knowledge. This case was treated with a long-pulse 1,064-nm neodymium:yttrium-aluminumgarnet laser.

\section{Key words}

Lower eyelid blepharoplasty; Neodymium:yttrium-aluminum-garnet laser; Periorbital vein 


\section{INTRODUCTION}

Lower eyelid blepharoplasty is a popular facial rejuvenation procedure. It is performed to improve the cosmetic problems of the lower eyelid and cheek. There are two main approaches to lower eyelid blepharoplasty. One is the first surgical technique, transcutaneous blepharoplasty, which is performed through a subciliary incision. The other is transconjunctival blepharoplasty, a surgical technique that leaves less permanent scleral show than transcutaneous blepharoplasty. The common side effects of lower eyelid blepharoplasty include an asymmetrical face due to postoperative edema, retrobulbar hemorrhage, chemosis, and ectropion. ${ }^{1-3}$

Herein, we present that the periorbital vein became prominent after lower eyelid blepharoplasty and it was improved through long-pulse 1,064-nm neodymium:yttrium-aluminum-garnet (Nd:YAG) laser.

\section{CASE REPORT}

A 32-year-old woman presented with complaints of a prominent bluish vein in her left infraorbital region after surgery. She underwent lower eyelid blepharoplasty four months previously. Postoperatively, she felt a little more pulling on the left infraorbital region than on the right side. As time passed, she found a bluish vein in her left infraorbital region. She had no remarkable medical or family history. The periorbital vein can be visually confirmed on the left infraorbital region (Fig. 1).

After obtaining informed consent, we performed two laser treatments on the prominent periorbital vein at onemonth intervals. The laser used was long-pulse 1,064-nm Nd:YAG laser (GentleMax ${ }^{\circledR}$; Candela Laser Corporation, Wayland, MA, USA). The parameters of the laser are as follows: 3-mm spot size, 20-ms pulse duration, and 130 $\mathrm{J} / \mathrm{cm}^{2}$ fluence. In addition, we applied a precooling time of $40 \mathrm{~ms}$ and a post-cooling time of $30 \mathrm{~ms}$. The laser was applied directly to the periorbital vein at $1 \mathrm{~cm}$ intervals. Medications or ointments were not prescribed after procedure, only a cooling mask was applied. The patient did not have any restrictions on daily life as usual. After laser treatment, the effect of blurring the periorbital vein was immediate, and the effect was maintained at the next visit. (Fig. 2A, B).

\section{DISCUSSION}

Lower eyelid blepharoplasty is a commonly performed surgery for facial rejuvenation, especially to resolve cosmetic problems on the lower eyelid or cheek. Lower eyelid blepharoplasty complications are very diverse, including postoperative edema, bruising, asymmetrical face, retrobulbar hemorrhage, blurred vision, and skin atrophy. ${ }^{1-3}$ As in our case, a prominent periorbital vein after lower eyelid blepharoplasty has not been reported yet to our knowledge; this should be considered as one of the side effects of this surgery.

In general, the periorbital vein becomes more prominent when the patient has fair skin or facial skin atrophy. ${ }^{4}$ In addition, periocular eyelid skin is very thin and has little subcutaneous fat, making it easier to notice periorbital vein. With aging, the skin under eyes may lose subcutaneous fat and elasticity and periorbital vein become more apparent. ${ }^{5}$ In our case, the periorbital vein appears to be prominent because her skin type was fair and after lower eyelid blepharoplasty, the skin was pulled and excessive

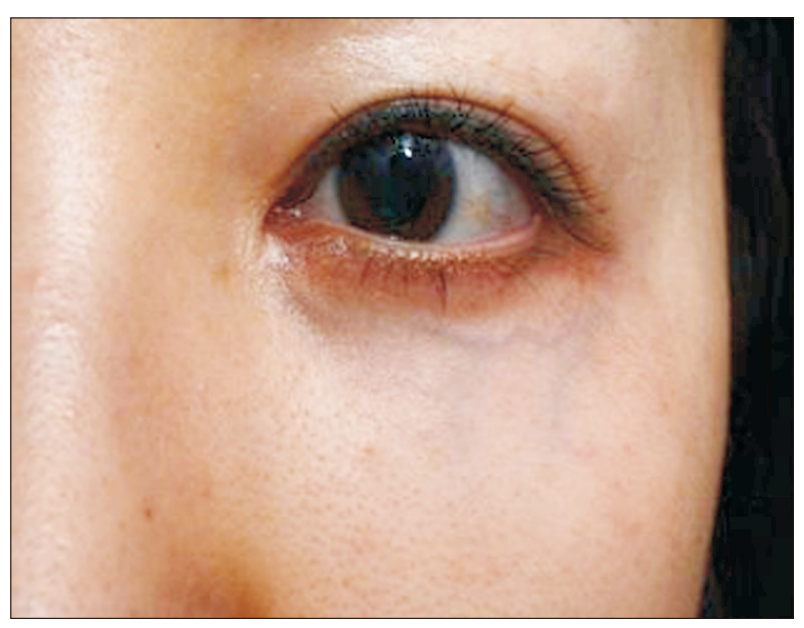

Fig. 1. After lower eyelid blepharoplasty, the left periorbital vein began to be visible.

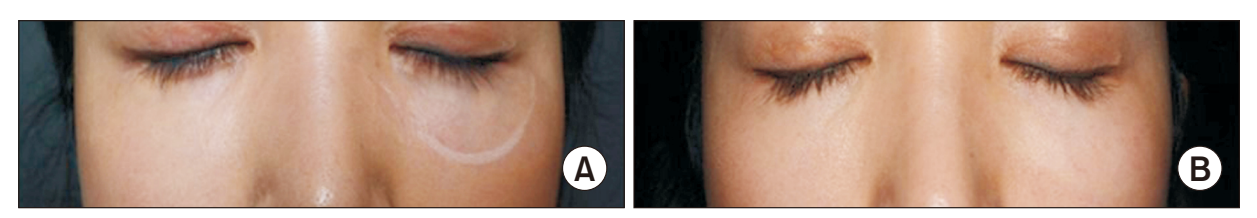

Fig. 2. (A) After undergoing laser treatment for the first time, the left periorbital vein is more blurred than before the treatment. (B) After undergoing laser treatment for the second time, the degree of bluishness becomes more blurred than the first laser treatment. 
amounts of subcutaneous fat were removed.

The periorbital part is one of the most conspicuous parts of the face, plays a significant role in meeting and communicating with people, and gives a sense of self-satisfaction. Because of these functions, various treatments exist for unsightly periorbital vein. Surgical treatments include sclerotherapy and ambulatory phlebectomy, which have been widely used for prominent periorbital vein in the past, but since they are invasive and can cause secondary complications, it is now preferred to use laserbased treatment. ${ }^{6}$ Laser types that treat vascular lesions include pulsed dye laser, potassium titanyl phosphate laser, long-pulsed infrared laser, and intense pulsed light. Among these, the long-pulse 1,064-nm Nd:YAG laser is more effective for deep and thick blood vessels. ${ }^{7}$ According to recent studies, there are many cases in which the prominent periorbital vein was treated using long-pulse 1,064-nm Nd:YAG laser. ${ }^{4,6,8-14}$ Prominent periorbital vein treatment with Nd:YAG laser is common at present, but we will be the first to treat prominent periorbital vein with $\mathrm{Nd}$ :YAG laser after lower eyelid blepharoplasty.

Although it takes several months to complete recovery after lower eyelid blepharoplasty, most patients feel presentable around 2-3 weeks after surgery. Reoperation is usually recommended to be done no earlier than 3 months later. ${ }^{1}$ When treating prominent periorbital veins with laser, laser treatment is not performed directly on the surgical site, and since the surgical site recovers within 1-2 weeks, laser treatment can be considered 3 months after surgery.

In conclusion, the prominent periorbital vein should be considered as one of the side effects of lower eyelid blepharoplasty; the long-pulse 1,064-nm Nd:YAG laser can be the optimal treatment.

\section{REFERENCES}

1. Julius FJ, Marco E. Blepharoplasty. In: Gurtner G Neligan P, editors. Plastic Surgery: Principles. London: Elsevier; 2017. p.295-325.

2. Branham GH. Lower eyelid blepharoplasty. Facial Plast Surg Clin North Am 2016;24:129-38.
3. Oestreicher J, Mehta S. Complications of blepharoplasty: prevention and management. Plast Surg Int 2012;2012:252368.

4. Chen DL, Cohen JL. Treatment of periorbital veins with longpulse Nd:YAG laser. J Drugs Dermatol 2015;14:1360-2.

5. Kersten RC, Kulwin DR. Management of cosmetically objectionable veins in the lower eyelids. Arch Ophthalmol 1989;107:278-80.

6. Chauhan N, Ellis DA. Periorbital rejuvenation: reticular vein treatment. Facial Plast Surg Clin North Am 2013;21:147-55.

7. James WD, Elston DM, Treat J, Rosenbach MA, Neuhaus IM. Andrews' Diseases of the Skin: Clinical Dermatology. 13th ed. Edinburgh: Elsevier; 2019. p.909-21.

8. Eremia S, Li CY. Treatment of face veins with a cryogen spray variable pulse width $1064 \mathrm{~nm} \mathrm{Nd:YAG} \mathrm{Laser:} \mathrm{a} \mathrm{prospective}$ study of 17 patients. Dermatol Surg 2002;28:244-7.

9. Goldman A, Lotti T, Tchernev G, Wollina U. Successful treatment of reticular blue veins of the lower eyelid by long-pulse $\mathrm{Nd}$ : YAG - case report with 8-year follow-up. Open Access Maced J Med Sci 2017;6:58-60.

10. Bevin AA, Parlette EC, Domankevitz Y, Ross EV. Variable-pulse $\mathrm{Nd}: Y A G$ laser in the treatment of facial telangiectasias. Dermatol Surg 2006;32:7-12.

11. Lai SW, Goldman MP. Treatment of facial reticular veins with dynamically cooled, variable spot-sized $1064 \mathrm{~nm} \mathrm{Nd:YAG} \mathrm{laser.}$ J Cosmet Dermatol 2007;6:6-8.

12. Bencini PL, Tourlaki A, De Giorgi V, Galimberti M. Laser use for cutaneous vascular alterations of cosmetic interest. Dermatol Ther 2012;25:340-51.

13. Aleisa A, Goldman MP. Dynamically cooled, variable spot-sized 1,064 nm neodymium-doped yttrium aluminum garnet laser as a treatment option for facial reticular veins. Dermatol Surg. In press 2020.

14. Lee TS, Kwek JWM, Ellis DAF. Treatment of periocular and temporal reticular veins with 1064-nm Nd:YAG Laser. J Cosmet Dermatol 2020;19:2306-12.

How to cite this article: Kim WJ, Cho HK, Lee SJ. Case of prominent periorbital vein after lower eyelid blepharoplasty treated with a long-pulse 1,064-nm neodymium: Yttriumaluminum-garnet laser. Med Lasers 2020;9:184-186. https://doi. org/10.25289/ML.2020.9.2.184 